\title{
Farklı desensitizerlerin dentin tübüllerine etkisinin incelenmesi: in vitro taramalı elektron mikroskop analizi
}

\section{Evaluation of the effect of different desensitizers on dentin tubules: An in vitro scanning electron microscopy analysis}

\author{
Çise NAZIM* I Ibrahim Levent TANER
}

Gazi Üniversitesi, Diş Hekimliği Fakültesi, Periodontoloji Anabilim Dalı, Ankara/TÜRKIYE

\section{Öz}

Amaç: Bu in vitro çalışmanın amacı Siyanoakrilat (Periacryl) ve tetra-kalsiyum fosfat ve dikalsiyum fosfat içeriklidesensitizerin (Teethmate) kombine ve tekli uygulamalarının kalıcılığının ve dentin tübüllerine etkisinin değerlendirilmesidir.

Gereç ve Yöntemler: Gömülü 20 yaş dişlerinden 140 dentin preparatı elde edilmiştir. Preparatlar 7 gruba ayrılmıştır ( $n=20$ ). Hiçbir uygulama yapılmayan preparatlar "K" kontrol, \%6 sitrik asitte 1 dk. bekletilenler PS (Periacryl) TS (Teethmate) PTS (kombine uygulama); 24 saat yapay tükürükte bekletilenler TY (Teethmate) PY (Periacryl) PTY (kombine uygulama) olarak gruplanmıştır. Uygulama tamamlandığında preparatlar SEM cihazı kullanılarak morfolojik yapıları, açık dentin tübül alanları ve açık dentin tübül çapları açısından değerlendirilmiştir.

Bulgular: Açık dentin tübüllerinin alanı kontrol grubuna kıyasla PS, PY, PTS ve PTY gruplarında azalmıştır ( $p>0,05)$. Numunelerdeki açık dentin tübül çap ortalamaları kontrol grubuna göre PS, PY, PTY, PTS ve TY gruplarında anlamlı derecede azalmıştır ( $p>0,05$ ). Sitrik asit uygulanan gruplarda istatistiksel olarak anlamlı bir farklılık yokken yapay tükürük uygulanan gruplarda açık dentin tübül çap ortalaması, PTY grubunda TY grubundan istatistiksel olarak anlamlı derecede küçüktür ( $p>0,05)$.

Sonuç: Periacryl dentin hassasiyet tedavisinde kullanılabilecek bir preparat olmakla birlikte kombine kullanımda Teethmate 'in kalıcılığını arttırmaktadır.

Anahtar kelimeler: SEM; Periacryl; Dentin Desensitizasyon

Sorumlu Yazar*: Çise Nazım, Gazi Üniversitesi, Diş Hekimliği Fakültesi, Periodontoloji Anabilim Dalı, Ankara/TÜRKiYE 


\begin{abstract}
Aim: The aim of this in vitro study is to evaluate the persistence of the combined and single applications of cyanoacrylate (Periacryl) and tetra-calcium phosphate + dicalcium phosphate containing desensitizer (Teethmate) and their effect on dentin tubules.
\end{abstract}

Material and Methods: 140 dentin samples were obtained from impacted third molars. The samples were divided into 7 groups ( $n=20$ ). Samples without any application named as $\mathrm{K}$ (control), samples were subjected to $6 \%$ citric acid solution for 1 min; PS (Periacryl) TS (Teethmate) PTS (combined application). Samples were immersed in artificial saliva for 24 hours named as; TY (Teethmate) PY (Periacryl) PTY (combined application). When the application was completed, the preparations were evaluated by scanning electron microscopy in terms of morphological structures, open dentin tubule areas and open dentin tubule diameters.

Results: The area of open dentin tubules decreased in PS, PY, PTS and PTY groups compared to the control group ( $p>$ 0.05). The mean diameter of the open dentin tubule in the samples was significantly decreased in the PS, PY, PTY, PTS and TY groups compared to the control group ( $p>0.05$ ). While there was no statistically significant difference in citric acid treated groups, the mean dentin tubule diameter was significantly lower in the group with artificial saliva than the TY group in the PTY group ( $\mathrm{p}>0.05)$.

Conclusion: Periacryl is a preparation that can be used in the treatment of dentin sensitivity, however, it increases the retention of Teethmate in combined use.

Keywords: sem; periacryl; dentin desensitization

\section{Giriş}

Dentin aşırı hassasiyeti, çeşitli sebeplerle ağız ortamına açılan dentinin termal, buharlaştırıcı, dokunsal, ozmotik veya kimyasal uyaranlara mazuriyeti ile oluşan; herhangi bir diş kusuru ile açıklanamayan; kısa, keskin, iyi lokalize ağrı olarak tanımlanır $[1,2]$. Dentin aşırı hassasiyeti toplumda önemli ve yaygın bir sorundur. Çalışılan popülasyona bağlı olarak; popülasyonun \% 8-35 i dentin aşırı hassasiyetinden şikâyetçidir. [3, 4].

Kabul görmüş dentin hassasiyet oluşum mekanizması hidrodinamik teoridir. Bu teoriye göre dentin hassasiyeti, dentin tübülleri içindeki sıvının hareketi sonucu pulpanın dış sınırında yer alan ve ani basınç değişikliklerine hassas olan sinir liflerinin uyarılması sonucu ortaya çıkar ve keskin bir ağrı ile karakterizedir. Dentin tübülleri içindeki sıvı termal, ozmotik, kimyasal herhangi bir uyaran sonrası hareket edebilir [5]. Dentin hassasiyetinin klinik semptomlarının açığa çıkma sebebi, dentin tübüllerinin; aşınma, erozyon, abfraksiyon gibi etkenlere bağlı mine kaybı ve / veya dişeti çekilmesi sonucu açığa çıkan kök yüzeyindeki sement kaybı sonrası dentin tübüllerinin ağız ortamına açılmasıdır[6]. Periodontal tedavi sonrası dentin aşırı hassasiyeti sıklıkla ortaya çıkmaktadır. Periodontal tedavi sırasında kazıma ve kök yüzeyi düzeltme işlemi yapılarak yüzey eklentileri ile birlikte hastalıklı sement de kaldırılmaktadır. Hastalıklı sement kaldırılırken dentin yüzeyinde smear tabakası oluşmaktadır, oluşan smear tabakası asitli yiyecek içecekler ve fırçalama gibi etkenlerle kolaylıkla ortadan kalkar ve açıkta kalan dentin tübülleri dentin aşırı hassasiyetine sebep olur. Dentin aşırı hassasiyetinin şiddeti yapılan periodontal tedaviye göre farklılık göstermektedir. Cerrahi periodontal tedavi sonrası sıklıkla dişeti çekilmesi ile iyileşme görülür. Çekilme sonucu açığa çıkan kök yüzeyi, dentin tübülleri ağız ortamına açıldığından dolayı hassasiyet yaratır. Ağız ortamına açılan dentin tübüllerinin tıkanması, sıvı hareketini dolayısı ile dentin hassasiyetinin klinik semptomlarını azaltabilir [7]. Dentin hassasiyeti tedavisinde mukogingival cerrahi, rezinler, pulpektomi gibi invaziv yöntemlerin yanında desensitize edici ajanlar ve diş macunları da kullanılmaktadır [8]. Etki mekanizmasına dayanarak, desensitize edici maddeler, sinir desensitörleri, protein çökelticiler, tübül tıkayıcı maddeler ve tübül örtücü maddeleri olarak sınıflandırıır [9]. Periodontal hastalık tanısı alan ve kök yüzeyi düzleştirme tedavisi gören kişilerin, dişeti çekilmesi olan sağlıklı bireylere oranla daha fazla dentin hassasiyeti şikayeti olduğu görülmektedir. Bununla birlikte, rahatsızlığı tamamen çözmek için etkili bir desensitizer maddenin bulunmadığını ya da durumun son derece subjektif doğasından ötürü mevcut tedavi seçeneklerinden bağımsız olarak tedavisinin zor olduğunu belirtilmektedir [10]. 
Son zamanlarda, tetra-kalsiyum fosfat [TTCP; Ca4 (PO4) 2O] ve dikalsiyum fosfat anhidröz (DCPA; CaHPO4) içeren bir materyal geliştirilmiştir (Teethmate [(TM), Kuraray Noritake Dental Inc., Tokyo, Japan]). Bu madde sulu ortamda hidroksiapatite dönüşür ki hidroksiapatit dentin ve minenin ana yapısında bulunur[11].

Siyanoakrilat doku yapıştırıcısı ağız içi kesilerde kullanılan ağız içi ortama biyouyumlu bir maddedir. Siyanoakrilat dentin tübüllerinin de kapanması ile dentin hipersensitizasyonunda kullanılabilir[12]. Furka defektleri üzerinde yapılan bir çalışmada lazerle karşılaştırılan siyanoakrilatın (2-oktil siyanoakrilat) lazerden daha etkili sızdırmazlık sağladığını göstermiştir[13].

Taramalı elektron mikroskobu (SEM), yüksek çözünürlüklü, 3D görüntüler ve topografik bilgiler sağlar aynı zamanda tübül oklüzyon seviyesini çok etkili bir şekilde gösterir. Dentin yüzeyindeki morfolojik değişimleri inceleyen çalışmalarda SEM cihazı kullanılmıştır[11].

Özellikle klinikte sıkça karşılaştığımız, periodontal ve mukogingival cerrahi tedavi kontrendikasyonu nedeniyle kök yüzeyinin kapatılamadığı hastalarda, dentin tübüllerinin lokal desensitizasyon ajanları ile tıkanması önem kazanmaktadır. Literatür incelendiğinde klinik çalışmalarda farklı materyaller kullanılarak farklı sonuçlar elde edildiği görülmektedir. Dentin hassasiyeti tedavisinde kullanılan pek çok farklı ajanın hassasiyet semptomlarını azalttığı ya da ortadan kaldırdığı bildirilmiş ancak materyallerin etkisinin kalıcı olmaması, araştırmacıları yeni materyal ve teknik arayışına yönlendirmiştir.

Hipotezimiz oral siyanoakrilatın (Periacryl) açık dentin tübüllerinin alanı ve çapında, Teethmate ve kombine uygulamaya göre daha etkin ağız ortamı toleransı ve aside dayanım göstereceğidir.

\section{Gereç ve Yöntemler}

\section{Örnek hazırlanma şekli}

Bu çalışmada 70 adet tam gömülü 20 yaş dişi kullanılmıştır. Gömülü 3. molar diş çekim endikasyonu olan hastalar öncelikle çekilecek dişleri ile ilgili bilgilendirildi ve hasta onam formu imzalandıktan sonra çekimleri yapıldı. Çalışma protokolü Gazi Üniversitesi Diş Hekimliği Fakültesi Klinik Araştırmalar Etik Kurulu tarafından onaylandı. (Etik Kurul Onay Tarihi: 21/06/2018 Karar: 2/1). Dişler en fazla 1 ay süre ile \%10 formol solüsyonunda bekletilmiştir. Çalışma için seçilen dişler hazırlanmadan önce yüzeylerinde kırık, çatlak ve çekim sırasında hasar görmemiş olduklarından emin olmak için incelenmişlerdir. Sağlam olan dişlerden elmas separeler kullanılarak mine sement sınırından ve $3 \mathrm{~mm}$ apikalinden olmak üzere diskler çıkarılmıştır. Daha sonra bu diskler ortadan ikiye bölünerek uygulama yapılacak preparatlar oluşturulmuştur. Uygulama yüzeyini sınırlandırmak, sement tabakasını uzaklaştırmak ve incelemede yanılma payını ortadan kaldırmak için her preparatın orta noktasına elmas fissür frez ile $3 \times 3 \times 1 \mathrm{~mm}$ boyutunda kaviteler açılmıştır. Dişler uygulama yapılana kadar serum fizyolojikte bekletilmiştir.

\section{Gruplara ayırma ve desensitizerlerin uygulanması}

Kavite açma sırasında oluşan smear tabakasını uzaklaştırmak için dişlere $5 \mathrm{dk}$. \%1 sitrik asit uygulanıp 10 saniye (sn.) distile su ile durulanmıştır. Oluşturulan preparatlar rastgele 7 gruba ayrılmıştır. Herhangi bir uygulama yapılmamış preparatlar kontrol grubu "K", Periacryl uygulanıp yapay tükürükte bekletilenler "PY", Periacryl uygulanıp sitrik asitte bekletilenler "PS", Teethmate uygulanıp yapay tükürükte bekletilenler "TY", Teethmate uygulanıp sitrik asitte bekletilenler "TS", kombine uygulama sonrası yapay tükürükte bekletilenler "PTY", kombine uygulama sonrası sitrik asitte bekletilenler "PTS" olarak kodlanmıştır. Uygulamada kullanılan desensitizerlerin üreticinin önerileri doğrultusunda kullanılmıştır. Uygulama sonrası dişler ağız ortamındaki dayanımını test etmek için yapay tükürükte (1.5 mmol// CaCl2, $50 \mathrm{mmol} / \mathrm{I} \mathrm{KCl}, 0.9 \mathrm{mmol} / \mathrm{KH} 2 \mathrm{PO} 4$, ve 20 $\mathrm{mmol} / \mathrm{ITris}, \mathrm{pH} 7.4) 24$ saat, aside dayanımlarını değerlendirmek için sitrik asitte (\% 6 wt pH 1.5) 1 dk. bekletilmişlerdir.

\section{SEM değerlendirmesi}

Uygulama sonrası preparatlar 24 saat kurumaya bırakılmıştır. Yüzey morfolojisi ve dentin tübüllerinde meydana gelen değişikliklerin değerlendirilmesi amacı ile SEM ile incelendi. Preparatlar kaviteler yukarıya bakacak şekilde alüminyum modüllere karbon bant ile yapıştırılıp kaplama için iyon püskürtme cihazına yerleştirildi. SEM cihazında incelenmek üzere 8x10-1 mbar vakum basıncında, $3 \mathrm{~mA}$ güçte, $270 \mathrm{sn}$. boyunca kaplandı. Daha sonra platin-altın alaşımı ile kaplanan örneklerSEMcihazındaincelenmeküzere $20 \mathrm{kV}$ ivmevoltajında, sıfır derece eğim açısında ve $11 \mathrm{~mm}$ çalışma mesafesinde incelendi. İvme voltajı Periacryl içeren numunelerde maddenin yanması sebebi ile 15 kVye düşürüldü. Her preparattan 1000x ve 2000x büyütme altında görüntüler kaydedildi. Elde edilen görüntüler, görüntü analiz programı ImageJ ile açık dentin tübüllerinin alanı ve açık dentin tübüllerinin çap ortalaması açısından değerlendirildi. Değerlendirmelerin tümü aynı araştırmacı tarafından yapıldı.

\section{Bulgular}

SEM görüntüleri görüntü analiz programı imageJ'ye yüklendi. Fotoğraflardaki dentin tübülleri manuel olarak işaretlendi (Figür 1b ). Dentin tübüllerinin sadece dairesel lümene sahip olanları değerlendirmeye alındı. SEM cihazı kullanılarak yapılan morfolojik incelemede dentin tübüllerinin uygulamalar öncesine kıyasla daha küçük olduğunu gösterdi (Figür 1). Sonuçlar tabloda verilmiştir(Tablo 1). Açık dentin 
tübüllerinin alanı kontrol grubuna kıyasla PS, PY, PTS, PTY gruplarında istatistiksel olarak anlamlı derecede azalmıştır. TY, TY gruplarında kontrol grubuna göre azalma görülse de istatistiksel olarak anlamlı bir farklılık görülmemiştir. Teethmate grubu, aside maruz bırakılan gruplarda da yapay tükürük gruplarında da anlamlı derecede fazla açık dentin tübül alanına sahiptir. Numunelerdeki açık dentin tübül çap ortalamaları kontrol grubuna göre PS, PY, PTY, PTS ve TY gruplarında anlamlı derecede azalmıştır. Sitrik asit uygulanan gruplarda istatistiksel olarak anlamlı bir farklılık yokken yapay tükürük uygulanan gruplarda açık dentin tübül çap ortalaması, PTY grubunda TY grubundan istatistiksel olarak anlamlı derecede küçüktür; PY grubuna göre ise azalma görülmesine karşın istatistiksel olarak anlamlılık gözlenmemiştir.

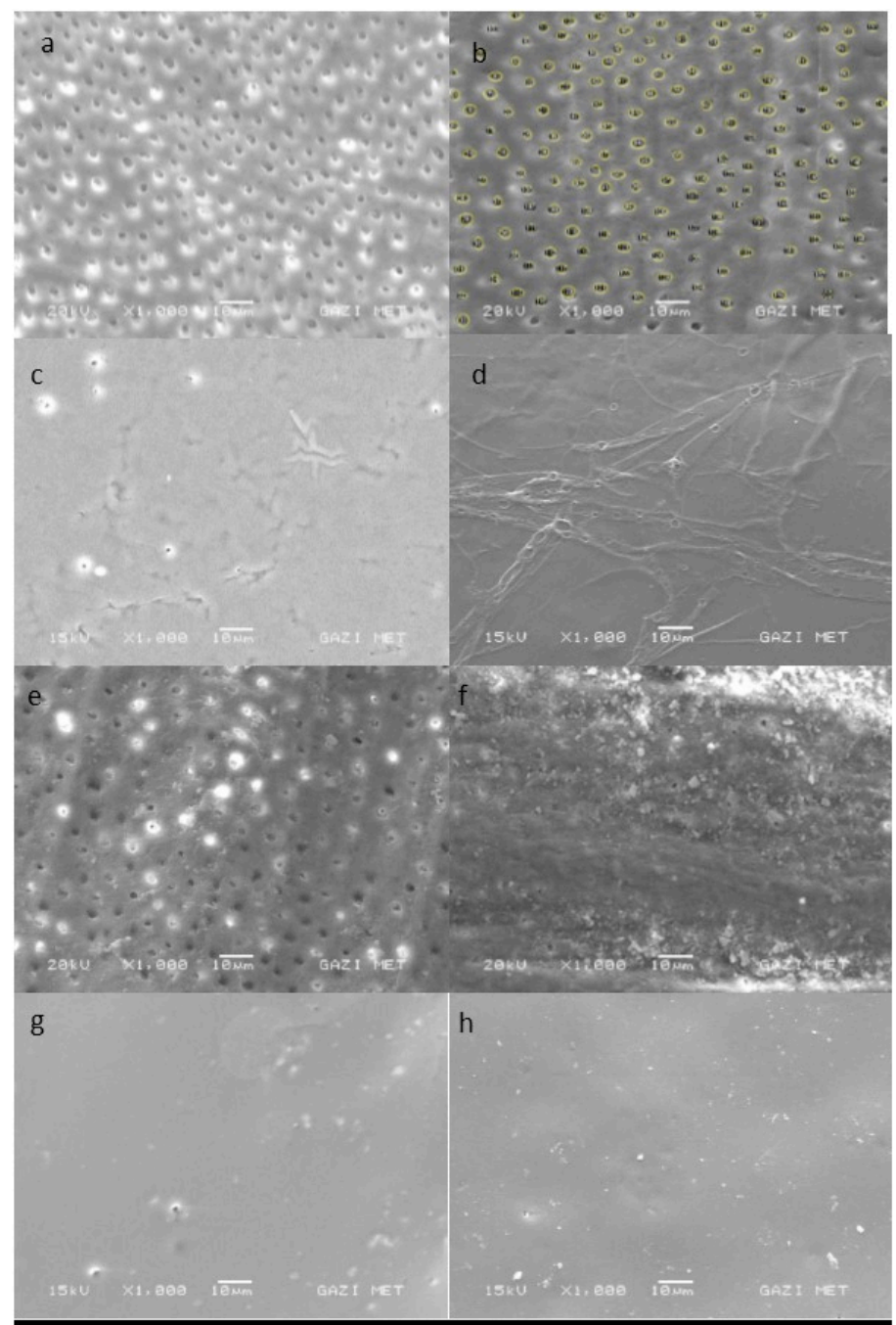

FiGUR 1 Uygulama yapılan grupların SEM analizi sonucu $\times 1000$ büyütmedeki görüntüleri a. Kontrol grubu b. Numunelerin imageJ programı kullanılarak işaretlenmesi c. PS d. PY e. TS f. TY g. PTS h. PTY

\begin{tabular}{|c|c|c|}
\hline Gruplar & $\begin{array}{l}\text { Açık Tübül Alan Toplamı } \\
\text { Ortalama } \pm \text { Std. Sapma }(\mu m) \\
\text { Ortanca (Min - Maks) }\end{array}$ & $\begin{array}{c}\text { Açık Tübül Çapı } \\
\text { Ortalaması } \\
\text { Ortalama } \pm \text { Std.Sapma }(\mu \mathrm{m}) \\
\text { Ortanca (Min - Maks) }\end{array}$ \\
\hline \multirow{2}{*}{ K } & $752,60 \pm 190,50$ & $2,82 \pm 0,28$ \\
\hline & $758,20(462,30-1109,00) a$ & $2,79(2,37-3,42) a$ \\
\hline \multirow{2}{*}{ PY } & $1,07 \pm 1,98$ & $0,79 \pm 0,64$ \\
\hline & $0,68(0,00-9,00) b$ & $0,96(0,00-1,61) b, c$ \\
\hline \multirow{2}{*}{ PS } & $1,63 \pm 2,02$ & $0,99 \pm 0,94$ \\
\hline & $0,57(0,00-6,10) b$ & $1,12(0,00-3,16) b, c$ \\
\hline \multirow{2}{*}{ PTY } & $0,66 \pm 0,99$ & $0,49 \pm 0,57$ \\
\hline & $0,12(0,00-3,36) b$ & $0,25(0,00-1,97) b$ \\
\hline \multirow{2}{*}{ PTS } & $1,35 \pm 1,79$ & $0,85 \pm 0,54$ \\
\hline & $0,88(0,00-7,20) b$ & $0,92(0,00-1,64) b, c$ \\
\hline \multirow{2}{*}{ TY } & $38,58 \pm 48,84$ & $1,26 \pm 0,18$ \\
\hline & $27,28(10,32-238,00) a$ & $1,24(0,95-1,66) c, d$ \\
\hline \multirow{2}{*}{ TS } & $97,49 \pm 30,11$ & $1,59 \pm 0,16$ \\
\hline & $101,10(25,84-154,60) a$ & $1,60(1,07-1,80) a, c$ \\
\hline
\end{tabular}

\section{İstatistiksel Analiz}

Elde edilen verilerin analizleri Prism GraphPad programı kullanılarak yapıldı. Çalışma verileri değerlendirilirken parametreler normal dağılıma uygunluk göstermediği için parametrelerin gruplar arası çoklu karşılaştırmalarında Kruskal Wallis testi ve farklılık çıkan grubun ikili karşılaştırmasında Dunn's çoklu karşılaştırma testi uygulandı. Anlamlılık $p<0,05$ düzeyinde değerlendirildi.

\section{Tartışma}

Dentin hipersensitizasyonu toplumda sık karşılaşılan ve yaşam kalitesini ciddi anlamda düşüren bir durumdur. Bu çalışmada oral siyanoakrilatın (periacryl) dentin hipersensitizasyonunda kullanılabilecek ağız ortamındaki sıvılara dayanıklı etkin bir ajan olması değerlendirilmiş ve onaylanmıştır.

Dentin hipersensitizasyonu ağız ortamına açılmış dentin tübüllerinin içindeki sıvı hareketi sonucu ortaya çıkar. Dentin tübül ağızlarının tıkanması veya daraltılması sıvı akışını durdurduğu veya azalttığı için klinik semptomlarda azalma görülür[5]. Yapılan bir derlemede dentin desensitizerlerin değerlendirildiği klinik çalışmalarda plasebo etkisinin çok yüksek olduğu gösterildi [14]. İn vitro çalışmalarda hasta faktörü ortadan kaldırıldığı için daha gerçekçi sonuçlar elde edilebilir. In vitro çalışmalarda, dentin diskleri üzerinden, dentinin morfolojik ayrıntıları, uygulanan maddelerin dentin tübülleri 
üzerinde tıkama veya örtme özellikleri, taramalı elektron mikroskobu (SEM) ölçümleri ile yapılır [15]. Çalışmamızda çekilmiş gömülü 20 yaş dişlerden elde edilen dentin örneklerine desensitizer maddeler uygulanmış ve sonuçlar SEM'de değerlendirilmiştir. Çalışmada kullanılacak dişlerin ağız ortamından etkilenip dentin tübül çaplarında değişim olması çalışma sonuçlarını etkileyeceğinden çalışmaya ağız ortamına maruz kalmamış tam gömülü 20 yaş dişleri dâhil edilmiştir.

Dentin desensitizerlerin anlık etkilerini değerlendirmenin yanında dayanımlarının ve ağız içindeki durumlara karşı ne tepki verdiklerini değerlendirmek de önemlidir. Çalışmamızda maddelerin sitrik aside ve yapay tükürüğe tepkileri tekli ve kombine uygulamalarla değerlendirmiştir. Çalışmamızın üstünlüğü anlık madde etkilerini değil etken sonrası durumu karşılaştırmasıdır.

Uyguladığımız in vitro çalışma modelinde maddelerin aside dayanımını test etmek için \%6 sitrik asit $1 \mathrm{dk}$. boyunca uygulanmıştır. Pereira ve ark. , asitli yiyecek ve içeceklerin yutana kadar ağız içinde oluşturdukları ortamın, \%6 sitrik asidin $1 \mathrm{dk}$. uygulanması ile taklit edilebileceğini söylemişlerdir[16]. Uygulanan maddelerin ağız içindeki tepkilerini değerlendirmek için 24 saat yapay tükürükte bırakılmışlardır. Yapay tükürük yıkama etkisinin yanında remineralizasyona da katkı yapmaktadır fakat 24 saat uygulamada bu etki görülmemektedir[17].

Teethmate uygulanmış dentin preparatları üzerinde yapılan morfolojik incelemede dentin tübüllerinin daralttığı ve açık dentin tübüllerinin alanında azalma sağladığı görülmektedir. Bu bilgiler literatürle uyumludur [18, 19]. Teethmate aside dayanıksız bir maddedir fakat kalın tabaka uygulamak dentin yüzeyini asitten korur[19]. Yapılan bir çalışmada Teethmate dentin tübüllerinin tamamını tıkayamadığı, parsiyel tıkama ile tübülleri daralttığı, 3 tabaka uygulandığı takdirde daha dayanıklı olduğu gösterilmiştir [20]. Bizim çalışmamızda da diğer çalışmalara benzer olarak yapay tükürükte bekletilen Teethmate preparatlarının açık tübül çap ortalaması kontrol grubuna göre istatistiksel olarak anlamlı daralma göstermiştir. Sitrik asitte bekletilen grubun SEM görüntülerine ise yapay tükürükte bekletilen gruba oranla daha az madde kaldığı açıkça gözlenmektedir. Bu maddenin sitrik aside olan dayanıksızlığını göstermektedir.

Periacryl, n-bütil siyanoakrilat ve 2-oktil siyanoakrilatın ideal bir karışımıdır. Doku adezivi olarak üretilmiştir ağız içi dokulara uyumludur. Yoğun kıvamlıdır, uygulama bölgesinde nemle karşılaştığında hızlıca film tabakası oluşturarak yüzeye bağlanır. Yaptığımız in vitro çalışmada bu özelliği SEM cihazında yapılan incelemelerde gözlenmiştir. Periacryl daha önce hiçbir çalışmada dentin hassasiyeti için kullanılmamıştır. Benzer bir madde olan Tisuacryl (n-bütil siyanoakrilat) doku adezivi dentin hipersensitizasyonu şikayeti olan hastalarda kullanılmış ve yüksek oranda başarılı bulunmuştur . Çalışmamızın sonuçları, Periacryl'in dentin yüzeyine hasar oluşturmadan etkili bir şekilde tutunduğunu; yapay tükürük ve sitrik asit muamelelerine dayanım gösterdiğini kanıtlar niteliktedir. Lazerin dentin desensitizasyonunda yalnız ve kombine tedavilerle etkinliği birçok çalışmada gösterilmiştir. Diğer taraftan dentinde kırık oluşturma ve yüzey distorsiyonu yapma gibi dezavantajları vardır[21]. Periacryl lazere göre ulaşılabilir ve ekonomik bir çözüm yöntemidir.

Kombine uygulamada amacımı Teethmate'in dayanımını arttırmaktı fakat aside dayanımları değerlendirildiğinde kombine kullanımda bir üstünlük gözlenmedi. Yapay tükürük gruplarında PTY, TY den daha anlamlı derecede yüksek başarı gösterdi. Kombine uygulama Teethmate'in toz yapısının, yapay tükürüğün yıkama etkisi ile uzaklaştırılmasını engellediğini söylenebilir.

SEM çalışmalarında mikrofotoğraflar üzerinden dentinin morfolojik ayrıntıları değerlendirilerek sayısal veriler elde edilir. Mikrofotoğraflar değerlendirilirken tam tıkalı tübülleri, parsiyel tıkalı tübülleri belirleyip yüzdelikleri alınarak her örnek için sayısal veriler elde edilebilir[22]. Çalışmamızda preparatlardan elde edilen mikrofotoğraflar ImageJ analiz programı kullanılarak değerlendirilmiştir. ImageJ analiz programı dentinin morfolojik değişimlerini numerik verilere çevirmekte kullanılan en etkin yöntemlerden biridir[23]. Çalışmamızda mikrofotoğraflar ImageJ programına yüklenerek açık dentin tübülleri manuel olarak işaretlenmiştir. Program işaretlemeler sonucunda açık dentin tübüllerinin alanlarını ve çaplarını hesaplamıştır. Alan hesaplaması açık dentin tübüllerinin çap ve sayı korelasyonunu vermektedir. Bu yöntem, parsiyel veya tam tıkalı gibi göreceli hesaplamalardan daha kesin sonuçlar sağlamaktadır.

\section{Sonuç}

Yapılan uygulamalar ile açık dentin tübül çap ve alanında etkin azalma sağladığını göstermiştir fakat siyanoakrilat içerikli Periacryl aside ve yapay tükürüğe dayanım açısından daha üstündür. Periacryl, dentin hipersensitizasyonunda kullanılabilecek bir preparattır ayrıca Periacryl ile kombine kullanımda Teethmate'in kalıcılığı artmaktadır. Periacryl'in etkisinin değerlendirilmesi için klinik çalışmalara ihtiyaç vardır.

\section{Çıkar çatışması / finansal destek beyanı}

Bu yazıdaki hiçbir yazarın herhangi bir çıkar çatışması yoktur. Bu çalışma Gazi Üniversitesi Bilimsel Araştırma Projeleri Birimi tarafından 032018/19 proje koduyla desteklenmiştir. 


\section{Kaynaklar}

1. Absi E, Addy M, Adams D, Dentine hypersensitivity. Journal of Clinical Periodontology 1987; 145: 280-84.

2. van Loveren $C$ et al. Dentin hypersensitivity management. Clinical Dentistry Reviewed 2018; 21: 6.

3. Gillam $D$ et al. Prevalence of dentine hypersensitivity in patients recruited for clinical trials. Journal De Parodontologie \& D'Implantologie Orale, Abstracts EuroPerio 1994; 1: 66.

4. Gillam DG. The Assessment And Treatment Of Cervical Dentinal Sensitivity.DDS thesis, University of Edinburgh, Edinburgh; 1992.

5. Brännström $M$, Lindén $L$, Åström $A$, The hydrodynamics of the dental tubule and of pulp fluid. Caries Research 1967; 14: 310-17.

6. Addy M. Dentine hypersensitivity: new perspectives on an old problem. International Dental Journal 2002; 52 : 367-75.

7. Pashley $\mathrm{DH}$, Dentin permeability, dentin sensitivity, and treatment through tubule occlusion. Journal of Endodontics 1986; 1210: 465-74.

8. Hypersensitivity, C.A.B.o.D., Consensus-based recommendations for the diagnosis and management of dentin hypersensitivity. Journal (Canadian Dental Association) 2003; 69: 221-26.

9. Gangarosa LP. Current strategies for dentist-applied treatment in the management of hypersensitive dentine. Arch Oral Biol 1994; 39: 101-106.

10. Gillam D, Orchardson $R$, Advances in the treatment of root dentine sensitivity: mechanisms and treatment principles. Endodontic Topics 2006; 131: 13-33.

11. Ishihata $\mathrm{H}$ et al. Effect of two desensitizing agents on dentin permeability in vitro. Journal of Applied Oral Science 2017; 251:34-41.

12. De la Caridad Pérez $M$ et al. Effectiveness and safety of tisuacryl in treating dentin hypersensitivity (DH). MEDICC review 2010; 12: 24-28.

13. Lopes-Silva AMS, Lage-Marques JL. Evaluation of the permeability of the furcation area of deciduous molars conditioned with Er: YAG laser and cyanoacrylate. Pesquisa Odontologica Brasileira 2003; 173: 212-16.
14. Rösing CK et al. Dentine hypersensitivity: analysis of self-care products. Brazilian oral research 2009; 23: 56-63.

15. Mordan N, Barber P, Gillam D, The dentine disc. A review of its applicability as a model for the in vitro testing of dentine hypersensitivity. Journal of oral rehabilitation 1997; 242: 148-56.

16. Pereira JC, Martineli ACBF, Tung MS. Replica of human dentin treated with different desensitizing agents: a methodological SEM study in vitro. Brazilian dental journal 2002; 132: 75-85.

17. Wang $Z$ et al, Effect of desensitising toothpastes on dentinal tubule occlusion: a dentine permeability measurement and SEM in vitro study. J Dent 2010; 385: 400-10.

18. Mehta $D$ et al. Randomized, placebo-controlled study of the efficacy of a calcium phosphate containing paste on dentin hypersensitivity. Dental Materials 2015; 3111: 1298-303.

19. Thanatvarakorn $O$ et al. In vitro evaluation of dentinal hydraulic conductance and tubule sealing by a novel calcium-phosphate desensitizer. Journal of Biomedical Materials Research Part B: Applied Biomaterials 2013; 1012: 303-309.

20. Zhou J et al. Effects of a dicalcium and tetracalcium phosphatebased desensitizer on in vitro dentin permeability. PloS one 2016; 11: 0158400.

21. Öncü E, Karabekiroğlu S, Ünlü N, Effects of different desensitizers and lasers on dentine tubules: An in vitro analysis. Microscopy research and technique 2017; 807: 737-44.

22. James JM, Puranik MP, Sowmya KR. Dentinal Tubule Occluding Effect of Potassium Nitrate in Varied Forms, Frequencies and Duration: An In vitro SEM Analysis. J Clin Diagn Res 2017; 118: 6-8.

23. Williams C, Wu Y, Bowers DF. ImageJ analysis of dentin tubule distribution in human teeth. Tissue and Cell 2015; 474: 343-48. 